\title{
Satisfaction among Residents over Recreation Facilities: A Case of Kasarani Neighbourhood in Nairobi City
}

\author{
Juliet Muiga $^{1}$, Robert Rukwaro ${ }^{2}$ \\ ${ }^{I}$ Department of Construction and Real Estate/Kenyatta University, Kenya \\ ${ }^{2}$ Department of Architecture and Building Sciences/ University of Nairobi, Kenya
}

\begin{abstract}
The purpose of this study was to establish satisfaction among residents on recreational facilities in Kasarani neighbourhood in Nairobi city. The study objectives were to examine the status of the existing recreational facilities, to assess the facilities needs of the Kasarani residents, and to identify interventions necessary for the gaps established in provision of recreational facilities. Methodological approach used primary data collection involved observations and administration of questionnaires to the officials of the Nairobi County Government, interviews with the Kasarani residents and managers of the recreation facilities. The study revealed the residents were not satisfied with the status of recreational facilities provision because they were inadequate in integrated planning, urban governance, planning standards, accessibility, safety, security, hygiene, maintenance, size, variety of services offered and their appropriateness for different users. Further, the study established that the location of recreation facilities was not appropriate; they were not affordable; they were not in proximity to the residents and were not available during the leisure time for different occupation and gender. Proper guiding policies to ensure provision of accessible and adequate facilities to all in the neighbourhood are also lacking. The study recommends different social groups residing in the neighbourhood be provided with accessible, affordable and adequate recreational facilities for satisfaction of residents. Further, planning, management and policy recommendations that inculcate both institutional and technical planning approach needed to be instituted.
\end{abstract}

Key words: neighbourhood, residents' satisfaction, recreation facilities, planning parameters, City of Nairobi

\section{INTRODUCTION}

The recreational activities fulfill psychological needs for a community that promotes socio cultural aspects and strengthen the individual health. They also meet the therapeutic needs of mind. Open recreational spaces are therefore necessary for their health physical and psychological development. According to Government of Kenya (2008), recreation is the sum total of all human, social-cultural and economic activities that enhances the therapeutic status of the mind. It brings a relaxation of the body and mind. The Government of Kenya (2008) outlines that recreational area as either private or public. They are provided for the following reasons; Need for relaxation after a long day work/break from routine, income generation/economic activities, social interaction, tourist attraction, set as carbon sinks/breathers, preservation of socio-cultural and or religious values, environmental conservation-forest, trees, flowers planting to safeguard against competing uses due to over population pressure hence overcrowding living conditions in the settlements. Government of Kenya (2001) recognizes the need for recreation among urban residents as it states recreation is necessary, is a motivating force in citizens' lives and should occur near home. Goodman and Freund 1968 emphasize the need to consider regional planning in recreation provision. They pointed out that shortage of the facility in one area causes the client population to travel to areas of surplus thus causing imbalance and congestion to the available facilities. This dictates a joint approach in planning and equitable distribution of such facilities even within a neighbourhood.Competition from the other urban land uses like housing and commercial activities, have led to low priority given to recreational open space allocation (Omondi, 1991). This argument is supported by Goodman and Freund (1968) who points out that recreational land use has settled at the bottom of the list of land uses. Rukwaro and Olima (2002) found out that social amenities among them playing grounds, meeting halls, open space and entertainment centres were least provided for by the developers. This shows lack of adherence to the established physical planning laws and regulations which states that any person who carries out development without proper approvals shall be guilty of an offence (Government of Kenya, 1996). Maina (1982) stresses that the government should have strong institutional framework that ensure the approved physical development plans are implemented to the latter. Reinforcing agencies in the institution should be well trained and ethical in their practice of development control. This is the only way to avoid unplanned 
development and grabbing of public social utility land.This study have selected Kasarani neighbourhood, which is one of the high density residential areas in Nairobi city, because of being bedeviled with lack of adequate land for social amenities although in some cases it was part of the initial development plan but was never implemented. The population of Kasarani neighbourhood has continued to increase at an alarming rate in last decade. Consequently, no expansion has occurred and this means the few existing recreational facilities are inadequate. The neighbourhood is known of having flats of over four storey height and maissonattes. The spatial planning of the Kasarani neighbourhood has not adequately catered for basic community facilities such as open spaces on which most of the recreational facilities are found. Therefore the residents have not enjoyed these recreational facilities as stipulated by Government of Kenya (2008). With this insight, the objective of this study are to examine the status of existing recreational facilities, assess the resident-satisfying needs, identify the inadequate provision of recreational facilities for the residents and finally develop the appropriate interventions to address residents needs in provision of recreational facilities.

\subsection{Types of Recreational Facilities and Their Uses}

Government of Kenya (2008) has identified major recreational facilities include: parks, sports complexes, entertainment and sports and social clubs among others. Each of these facilities is outlined below. Public parks are determined by their topography, historical and social cultural aspects of local population. Parks provide a range of recreational prospects such as the following: scenic sites for picnic, areas for sitting in quiet gardens, shaded path and trails for walking through, areas for botanical collections and exhibitions; areas for open air exhibitions of sculpture, paintings and photography; areas of flat expanse which encourage ball games, running about and exercising in addition to providing space for displays, fairs, shows, areas for organized sports such as cricket and tennis courts; arena for open air display of traditional dancing, plays, concerts, shows and mass meeting; developed artificial lakes and pools, ornamentals, boating, fishing, collection of water plants and waterfalls and children play groups.The areas for recreation includes: Areas of scenic beauty, areas of historic/ cultural importance, unique physiographic features, parks, forests, water masses such as; play fields, stadia, green spaces, zoos, snake parks, museum, amusement parks, discotheques and cinema halls, conservation areas and road reserves (Government of Kenya, 2008).Public parks can be located in areas unsuitable for buildings such as along streams, hill slopes, areas of rock outcrop and in conjunction with conservation or forestry projects. Open areas suitable for sports and play areas should not be designated for other purposes. Open spaces should be designed in combination with pedestrian ways, water standpipes, areas of natural drainage and areas requiring conservation. An ideally planned city has a hierarchy of recreation areas that range from urban parks to serve entire city population, to district and neighbourhood parks meant to serve a group of estates and individual estates (Omondi, 1991). The facilities should meet minimal standards according to stipulated physical planning laws and regulation (Government of Kenya, 2008).The activities found in sports complexes should include; yachting marina, athletic tracks, centers, indoor games, hard courts, swimming pools, golf and putting rangeswith spectator facilities, catering establishments among others. They should be easily accessible through public transport. The facilities for entertainment include theatres, cinemas, restaurants and nightclubs developed within in the central areas of the neighbourhood. They grow depending on the expansion of neighbourhood. Sports and social clubs private clubs which provide facilities for various sports or games e.g. golf, tennis, squash, swimming etc., together with club houses for social and cultural exchange. The satisfaction of the residents on the provided facilities in the public parks depends on the extent to which they meet the minimum physical planning standards.

\subsection{Planning of Open Spaces for Urban Neighbourhood}

According to Goodman and Freund (1968) open space is defined as space which is not used for buildings or structures. Space is the counterpart of development. It may be air, water, land located in a "big city" or in remote from urban development. They further stressed that whatever use the open spaces are put into usually affects the adjoining building development patterns and vice versa.There are basically three major functions of open spaces in an urban neighbourhood (Goodman and Freund, 1968). These are; meet positive human needs both physically and psychologically in recreation amenities, enhance and protect the resource base like air, water, soil, plants and animals, and it affects economic development decisions like tourism, development patterns, employment and real estate values. The location and design of open space can play an important role in bringing people together as in a neighbourhood park, an apartment courtyard or a clustered subdivisions open area. Alternatively, it can create barrier separating different uses or neighbourhoods.Local open spaces and major open spaces are two categories of public open spaces for urban areas. Local open space should be provided to clusters of houses at a preferred rate of $10 \mathrm{~m}^{2}$ per household to cater for the needs of the resident population (e.g. sitting areas, toddlers play). The local open space should within $100-150 \mathrm{~m}$ distance from the house, which is regarded as a maximum distance for a toddler's play area in a housing cluster. Sometimes it is difficult to identify boundaries between plots, roads and unutilized open spaces. In such 
instances, the local open space, including tertiary roads and pedestrian ways, should occupy $20-25 \%$ of the total area (Government of Botswana, 1997).Major open space shall be provided at $6 \mathrm{~m}^{2}$ per household to provide the necessary sports fields, play areas recreational parks, biological diversity reserves and others. This standard is made possible by providing sport fields and play areas for the more grown up children (10 years and older) and a place for recreation, within 500 metres maximum walking distance.

\subsection{Integrated Planning for Human Recreation}

According to Goodman and Freund, (1968) the design of recreational areas are tied to policies of other community facilities. The sustainable recreational areas cannot be undertaken as a single function. It must be integrated into other land uses such as economic, social and transportation networks for it to be effective and efficient. To have resident-satisfying recreational facilities in the neighbourhood, the planner must ensure designated areas are accessible, functional, aesthetical and hygienic. Omondi (1991) suggests that for sustainable provision of urban recreation facilities, there should be systematic and continuous analyses of trends in demand for recreation so that their provision can keep pace with changes in the demography and spatial growth of the neighbourhoood. This emphasizes the need for behavioural data to direct recreational facilities plans and programs and regular review of regulations guiding their planning and use. The socio-economic factors of urban residents in Kenya have a strong attachment to land and that informs their comprehension of recreation (Government of Kenya, 2008).

\subsubsection{Affordability and proximity location}

The low earning of most of the urban residents impacts on transport cost and charges at recreation facilities. Government of Kenya (2008) notes that recreation facilities should be within a walking distance from residents home to minimize travelling cost. The recreation facilities should be within 500 metres maximum walking distance for grown up over 10 years and a maximum of $100-150$ metres from the house for toddlers play area in a neighbourhood cluster (Government of Botswana, 1997). The sport fields according to Goodman and Freund, (1968) should be suitably located within walking distance and within convenient driving range within neighbourhood.Because of the economic status of most households, Government of Kenya (2008) recommends that the recreational facilities should be attractive and inexpensive for most of its users. Design of landscaping elements and other facilities for recreation should be based on the principle of affordability and accessibility of residents.

\subsubsection{Age cohort}

Government of Kenya (2008) has identified there should be recreational spaces for different age groups. This gives the users an opportunity for independent play and exploration of spatial experience in relaxation. For example, a child wants to play in safe attractive and stimulating surroundings within the residential areas. Such recreational spaces should avoid overcrowding that might cause stress which makes them lose their core purpose of relaxation. Omondi (1991) outlined the qualities of a park as: a corner for toddlers and pre-school children with low fence hedge or barriers, shade, open area for running and circle games, swings, balance beams and horizontal bars.

\subsubsection{Security}

Understanding the behaviour of residents is important in planning for parks as demonstrated by Goodman and Freund (1968). These authors observed that one large metropolitan park system discovered people were venturing only about 30 metres from their parked cars in the parks. The reasons for this behaviour varied, ranging from fear, not of being raped or mugged behind the laurel bushes but of being in totally strange, alien and unknown terrain. This prevented them from freely exploring untapped nature in the inner reaches of the park. The wilderness in the parks is one of the experiences that should not be deterred by fear of crimes occurring there. To fight crime in the park, there is need of one specific and large group of users to move together and more security to be enforced.

\subsubsection{Planning standard}

In urban areas, where the land uses are competing, it is important to give the recreational areas their due proportionate of $20-25 \%$ of neighbourhood area (Government of Botswana, 1997). This percentage considers also all open areas left in the neighbourhood area. In essence recreation spaces offer places such as scenic sites, parks, stadia, cinema halls, restaurants and theatres among other for body and mind relaxation.Government of Kenya (2008) has stipulated that recreation places should have a public access of minimum of nine metres wide road and at least 0.4 hectares to cater for car parking spaces, picnic site and refuse disposal facilities. Further, recreational places should be compatible to surrounding land use patterns, cultural values of the local population and should not be harmful to the natural attraction of the area. A well maintained 
road reserve can also be used as a recreational place. Recreational space should be within walking distance of all areas with a residential density above 50 persons per hectare. Parks shall be 1-2 hectares per 10,000 populations in areas above 50 persons per hectare (Government of Kenya, 2008). Only if these planning standards of recreation areas are met those residents are satisfied of provided recreational places.

\subsubsection{Participation of residents in planning and management of recreational facilities}

Several authors agree on residents' participation in planning and management of recreational facilities as a remedy to the provision and sustainable maintenance of these facilities. UN Habitat (2002) emphasises community participation in provision of basic services that lead to cost recovery and long term sustainability of services. Horn (2001) calls for community participation in local area planning and management. Kokor (2001) sees community participation as enhancing sustainable yield of common property resources such as recreational facilities and the benefit spreads evenly. Planning of recreational areas should involve the residents to understand their ideas and behaviour.The residents are more satisfied with the recreation services provided if they participated in indicating their fulfilled needs in recreating. Some of the planning and design aspects of recreation spaces that should be considered are: functionality, demographic factors, socio-economic and cultural factors, maintenance, distance, mode of transport, and residents' participation in the inception stages of the project.

\section{2. RESEARCH METHODS}

The study was conducted in Kasarani location in North Eastern side of Nairobi, Kenya which covers an area of 11.8 square kilometres (Figure 1). The main urban features and landmarks within the area of study are; the Moi International Sports Complex - Kasarani, the Kenya Institute of Special Education (KISE), International Centre of Insect Physiology and Ecology (ICIPE), Thika Road Mall (TRM), Regional Centre for Mapping of Resources for Development (RCMRD) and Haco industries. The neighbourhood borders the Safari Park Hotel, Garden City, the East African Breweries factory, Queen of Apostles Seminary among others. It is also linked to other neighbourhoods by elaborate road networks which include the 12 lanes Nairobi-Thika superhighway and Kasarani Mwiki road. The residential zones in the area of study are Clay City, Sports View Estate, Kasarani Estate and Kasarani Police Divisional Headquarters. Kasarani is distinctive in that it is one of the fastest growing peripheral neighbourhoods in Nairobi City. It was chosen because of inadequacy of recreational facilities compared to the large population growth of 4.3 per cent. The study area had a total population of 525,624 in 2011, of which male gender constituted 266,684 and female 258,940, in 2011 (Kenya National Bureau of Statistics, 2011). The total households were 164,354, occupying 86.4 square kilometres, with a population density of 6,082. The youth were defined as those aged between 20 and 40 years comprised 30 per cent of the population and are known to have great desire for recreation (Kenya National Bureau of Statistics, 2009).Direct observation was done to ascertain the built form status of the recreational facilities. This involved physical observation of features such as infrastructure and existing land usage in the neighbourhood and the reconnaissance to update the maps and images. The checklist for observation covered land uses, physical conditions of existing facilities, social groups and recreational spaces. Photography was used to collect observational data on the state of recreational facilities in the area and different ways in which the residents engaged in leisure activities.Stratified sampling method was used to select the households. This method was relevant since the study aimed at capturing information from all the diverse built forms e.g. flats, bungalows and maisonettes. Each stratum of population had fifty households which were randomly selected for the interview. Random sampling was done to the residents who use the recreation facility in Kasarani neighbourhood.Four questionnaires were allocated to each recreational facility. 40 questionnaires were administered at the identified 10 recreational facilities to users. The questionnaires were designed to assess their satisfaction on the recreational facilities offered within Kasarani neighbourhood. Further, they inquired on the socio-economic data sought from recreational facilities users. This included data on income sources and amount per month, age, religion, level of education and purpose of engagement either for recreation activity or for competition for commercial/career interests, distance covered to recreational facilities access, incidence of usage and frequency and level of usage. Type of recreational facility and factors leading to choice of a particular facility and its level of adequacy and accessibility was established. The rating of their satisfaction on recreation facilities was measured using ranking methods. Questionnaires were administered to heads of households, managers and users of public and private facilities. A total of 56 questionnaires were administered to household heads. They captured resident data on the social and economic characteristics. Further information required included level of awareness on activities at different facilities and preferred time to visit facility and reasons for not visiting the facilities regularly if any.Key informants interviews were held with key opinion leaders in neighbourhood. The Nairobi City Council physical planning officials concerned with planning and maintenance of recreational facilities were also interviewed together with 10 managers of recreational facilities and learning institutions, both private and public.The officials Urban Development Control and Compliance and Reinforcement Sections 
of Nairobi City County (NCC) were administered each one questionnaire. The study investigated the challenges facing the NCC with regard to provision and day to day management of recreational facilities to the neighbourhoods and examined how the NCC management plans to overcome the identified challenges. There were questions on priority given to recreation services in resource allocation, maintenance and legal backing to the planning regulations. The institutional framework issues were inquired from the NCC personnel. The coordination between NCC, private developers and residential communities and the role of each was covered with the aim of assessing the possibility of community engagement in recreational facilities provision, maintenance and management.

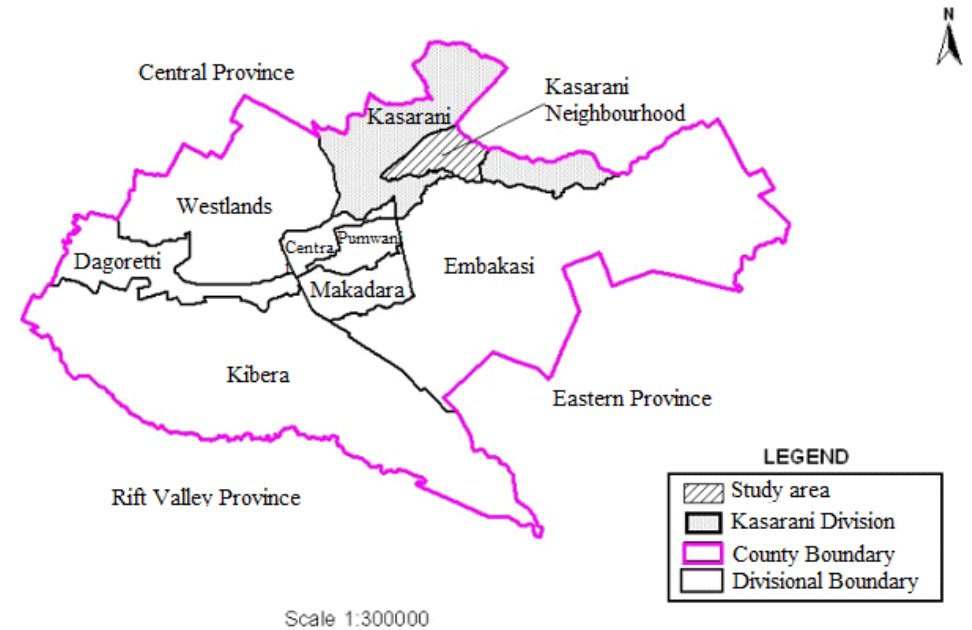

Figure 1: Map of Nairobi Province showing the study area Source: Nairobi City Council (1981)

\subsection{Kasarani Neighbourhood Recreational Facilities Context}

\section{3. RESULTS AND DISCUSSION}

\subsubsection{Ownership, type and use}

The private recreational facilities had grown rapidly and estimated to be $60 \%$ of Kasarani recreational facilities. This state of affairs was likely to continue for a long time due to increased urban growth and inability of the Nairobi County government to provide adequate recreational facilities particularly the upper low-income and middle income social-economic class residents in the area. The type and uses of recreational facilities in Kasarani are shown in Table 1.

\begin{tabular}{|l|l|l|l|}
\hline & Type of recreational facilities & Uses & Ownership \\
\hline 1 & $\begin{array}{l}\text { Kasarani sports complex ( } \\
\text { stadia) }\end{array}$ & Sports, aerobic and boxing & Public \\
\hline 2 & Kasarani Sport view hotel & $\begin{array}{l}\text { Sauna, gymnasium \& Children } \\
\text { play areas entertainment place }\end{array}$ & Private \\
\hline 3 & Hotel Monaco & $\begin{array}{l}\text { Entertainment place; Pool table } \\
\text { \& wide screen TVs }\end{array}$ & Private \\
\hline 4 & $\begin{array}{l}\text { Community playing fields } \\
\text { (neglected) }\end{array}$ & Not in use & Public \\
\hline 5 & Kasarani aquatic complex & Swimming & Public \\
\hline 6 & Roysambu roundabout & Leisure park & Public \\
\hline 7 & Thika Road Mall(TRM) & $\begin{array}{l}\text { Window shopping, children } \\
\text { games Private }\end{array}$ & Pranged use into a Korean \\
\hline 8 & Community centre & $\begin{array}{l}\text { Private } \\
\text { church }\end{array}$ \\
\hline 9 & Schools' playing grounds & Football, handball & Private \\
\hline 10 & Road reserves & Children playgrounds, cycling & Public \\
\hline
\end{tabular}

Source: Field survey, 2016 


\subsubsection{Recreational activities}

The residents of Kasarani neighbourhood engage in different recreational activities during leisure time. 53\% of the residents interviewed at household level engaged in passive leisure activities while the rest involved in active activities. The passive activities mostly participated by residents ranged from listening to music to storytelling. Most of the different passive activities were held in-doors in residences and are shown in Pie-chart 1 .

Pie-Chart 1: Passive indoor recreational activities

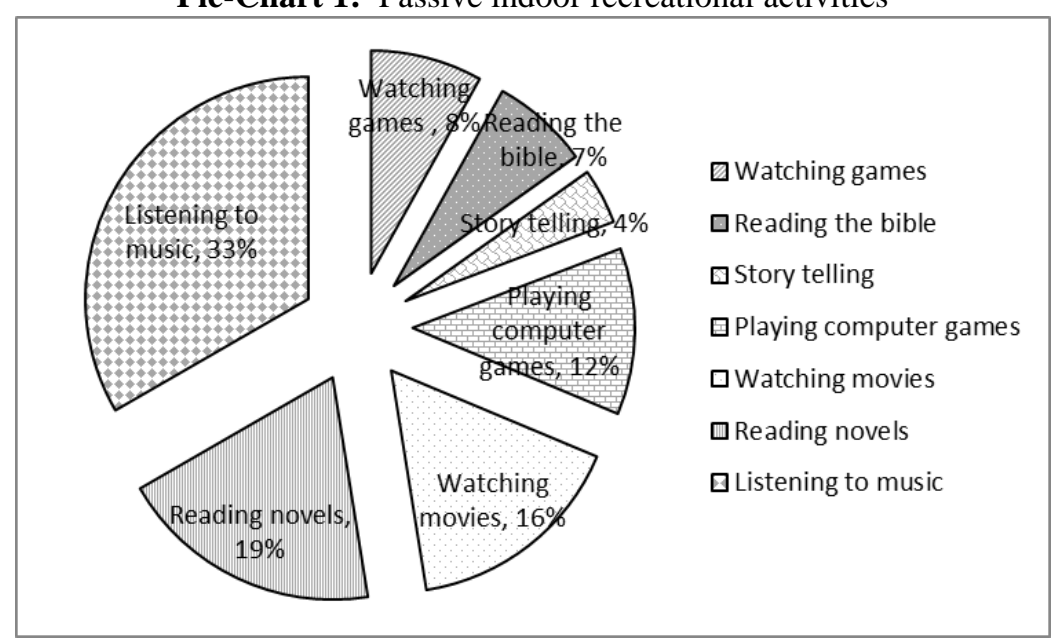

Source: Field survey, 2016

The most participated active activities included football playing and activities in the gymnasium such as aerobic and boxing. The other activities engaged in are shown in Pie-chart 2 . This study revealed that majority of residents in the neighbourhood did not exert much significant physical or mental energy or built a person's skills or self-confidence as advocated by Disio (1982). The reasons advanced for not engaging in outdoor active leisure activities were lack of open fields nearby (36\%), people health (26\%), and attractiveness of facility (18\%), affordability (14\%) and security concerns (6\%). These were issues that need to be addressed for facilities to attract the users who were looking for active leisure activities to enhance their existence and enjoyment during leisure periods.

Pie-Chart 2: Active outdoor recreational activities

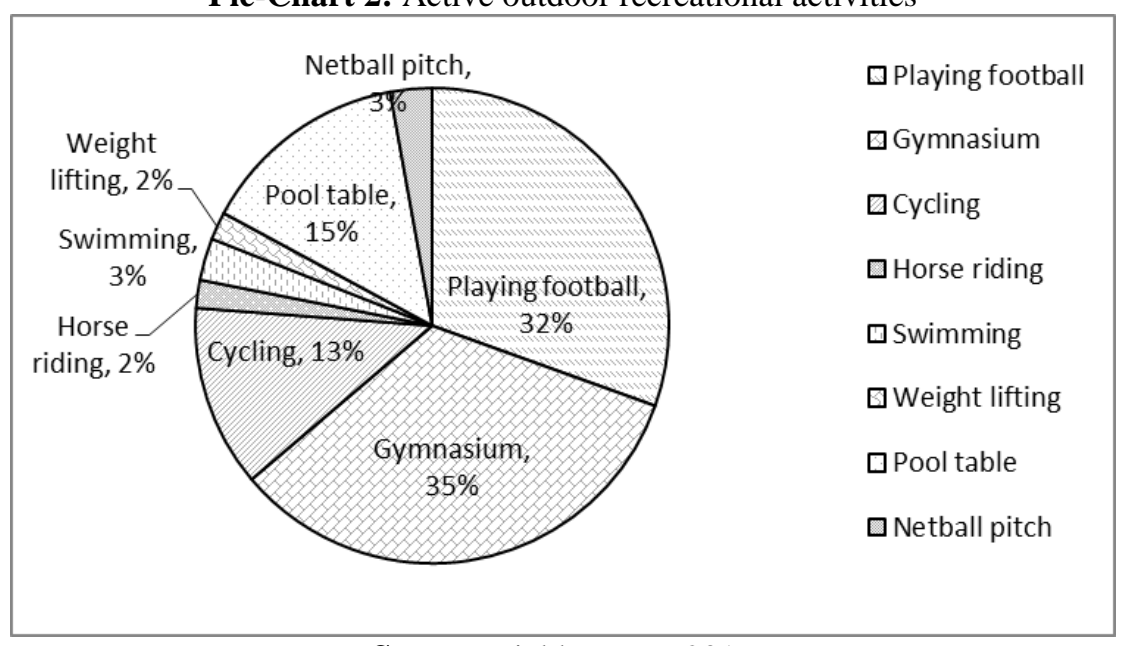

Source: Field survey, 2016

\subsubsection{Using trend}

Among the facility managers interviewed on the trend of facility utilization said that $10 \%$ of the facilities indicated stagnant growth, $60 \%$ were in upward trend and 30\% shown downward trend. The reasons given for the upward trend were; improved customer service, urban dwellers were becoming more aware of the benefits of recreational activities and few facilities were located in close proximity to the residents' homes offering such customers convenience. Reasons for downward and stagnant trends were attributed to competition 
from upcoming facilities resulting to customers drift and consequently low income turnover. $60 \%$ of the managers felt that their facilities were fully utilized, while only $20 \%$ of facilities had an average of $60 \%$ capacity. This implied that if more residents in the neighbourhood were mobilized to participate actively in the recreational activities, the facilities were inadequate. Some facilities such as Kasarani aquatic complex did not have instructors to train residents on how to swim or improve their swimming skills. This greatly influenced its level of utilisation.

\subsection{Satisfaction among Residents}

Items on resident questionnaire addressed both quality and planning standards of recreational facilities issues along 5-point continuum from 1 (very dissatisfied) to 5 (very satisfied). The level of satisfaction was quite low across several domains (Table 2). Qualitative feedback from residents presented below explains these results.

Table 2: Satisfaction among residents

Question: What is your level of satisfaction on this/these aspects of recreational facilities?

\begin{tabular}{|l|l|l|l|}
\hline & Rating scale of item statement & Mean & $\begin{array}{l}\text { Standard } \\
\text { deviation }\end{array}$ \\
\hline 1 & Available and large capacity & 2.68 & 1.29 \\
\hline 2 & Well maintained and hygienic & 2.23 & 0.87 \\
\hline 3 & Reasonably affordable & 2.55 & 0.96 \\
\hline 4 & Ideally located - nearby & 2.73 & 1.05 \\
\hline 5 & Good security and safety & 1.69 & 0.59 \\
\hline 6 & Available age cohort activities & 1.71 & 0.61 \\
\hline 7 & $\begin{array}{l}\text { Easily used by gender and people of different } \\
\text { occupation }\end{array}$ & 3.23 & 1.23 \\
\hline 8 & Wide ranging recreational services & 1.87 & 0.71 \\
\hline 9 & Well planned standardised & 2.36 & 1.09 \\
\hline 10 & Well managed by stakeholders & 2.32 & 1.00 \\
\hline
\end{tabular}

Source: Field survey, 2016

Note that forty resident facility users responded. Each item was rated on 5 point scale ranging from 1 (very dissatisfied) to 5 (very satisfied).

\subsubsection{Size and availability}

$85 \%$ of the respondents considered size of the facility when making a choice. Large facilities host several activities at the same time thus they were available for use most of the time. Private facilities in Kasarani like Kasarani Sports View Hotel and Hotel Monaco, were mostly congested due to their small size against the number of users requiring their use during the peak periods. The peak time for most facilities included the weekends $(60 \%$ public holidays $(30 \%)$ and weekdays $(10 \%)$. As most residents were Christians, Sunday was reserved as an outing day and this was observed as peak time for use of recreation facilities in Kasarani. The most used facilities were the swimming pools, children swings and slides (Figure 2).

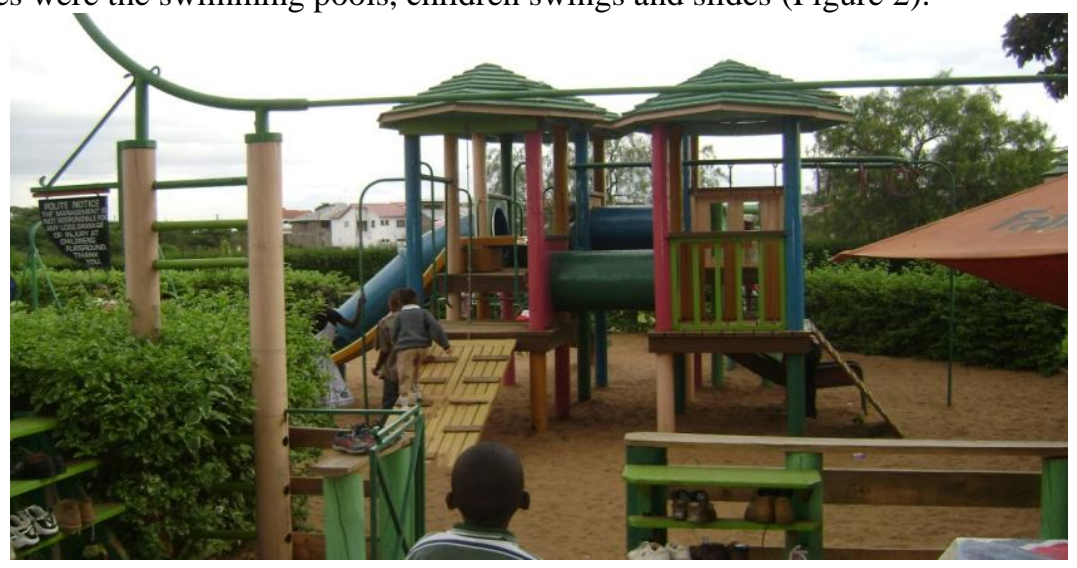

Figure 2: Sports View Hotel, a recreational facility Source: Field survey, 2016 


\subsubsection{Maintenance and hygiene}

$60 \%$ of the recreational facilities were built 15 years, $20 \%$ were constructed between 6 and 10 years old, and $20 \%$ were created between 10 to 15 years in ago. There was noted a trend that newer facilities were better maintained than older ones.95\% of the respondents indicated that they preferred functional facilities in a clean state. Observation of the public facilities showed that they were not well maintained especially the old facilities. Cleanliness of the Kasarani Aquatic Complex facilities was not adequate especially the two shallow swimming pools which were mostly overcrowded (Figure 3). $70 \%$ of the respondents said the public recreational facilities were crowded and this meant increase of the recreational facilities needed to be addressed by the physical planner at Nairobi City County Government. Crowding had a psychological effect on the participants. The overcrowded facilities were not appealing and were perceived as being of low hygienic standard. The sanitation facilities for disabled person were missing in most recreational facilities.

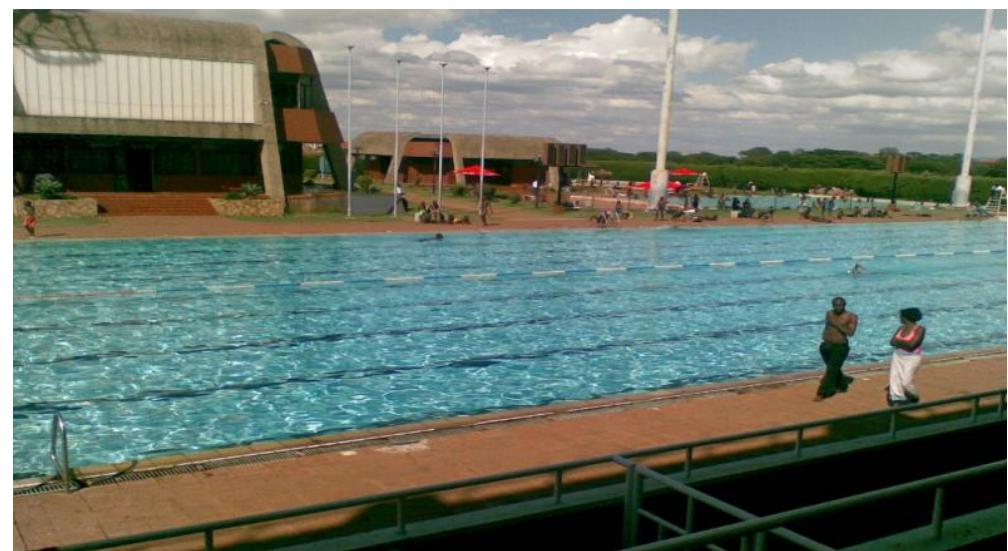

Figure 3: Baby pudding (back ground) and the competition pool in the foreground Source: Field survey, 2016

\subsubsection{Affordability}

Affordability was viewed as the amount the residents were willing to pay to get access to the recreation facilities, which included travelling costs and fees charged for entry. 80\% of users of the recreational facilities felt that affordability was a very important factor in the choice of a recreational facility. The fees charged were opposed by residents who needed recreation as it was unaffordable. $55 \%$ of respondents viewed the recreation facilities as a public service by government to its citizens while the reality was that many public recreation facilities were becoming less inclusive and public due to introduced fees. Income of the household was a major determinant of using the recreation areas which charged entry fees.

However, some users felt that affordability highly depended on the quality of service and the satisfaction one got from the facility usage. Users were ready to spend more on good recreational services which were mostly private facilities rather than public facilities which offered cheap poor services. Private recreational facilities had minimal involvement of the residents, whereas the public facilities attracted volunteer support from the neighbourhood.Pie-Chart 3 shows the amount of money spent per household on recreation. $45 \%$ of respondents were economically weak with $50 \%$ of the households spending less than 40 dollars a month while $15 \%$ spent nothing on recreational pursuits.

Pie-Chart 3: Amount of money spent per household on recreation

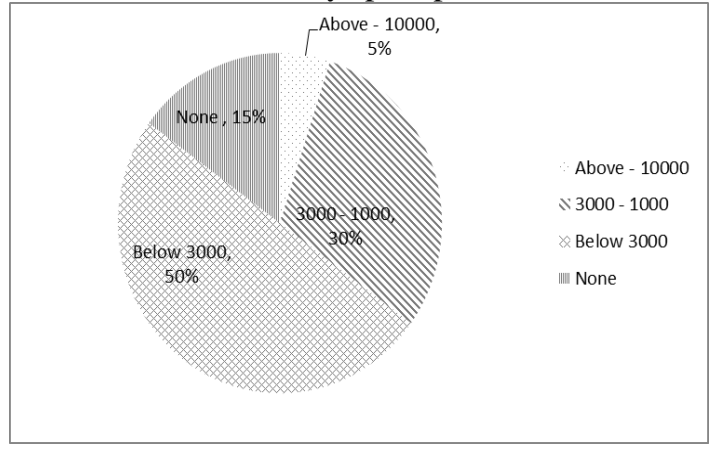

Source: Field survey, 2016 


\subsubsection{Proximity and location}

Only $15 \%$ of households travelled outside the neighbourhood like Village Market about 10 kilometres from Kasarani to satisfy recreational needs. The furthest facility was two kilometres from estate. It was likely that the low mobility was as a result of avoidance of travel costs. Further, the inadequate and lack varied facilities located within the neighbourhood made the resident participate more in passive recreational activities or travel far for search of better recreational facilities. $75 \%$ of the respondents considered location of the facility as an important factor in the choice of a particular facility. Some facilities such as the public playing field were located at the edge of the neighbourhood to the extreme southwest corner, sandwiched between three private properties and the other side were the septic tanks. The field was near the low density residential zone in the western side of the neighbourhood. The children from the high density high-rise flats residential zone in the eastern side had to cross the busy 30 metres Kasarani road and several other 15 metres access roads to access this important public facility. This play field had low usage and this can be attributed to its poor location. Lack of safe crossing mechanisms to the open space greatly hindered easy access to the facility by the sick, aged, children and the physically challenged residents (Figure 4).

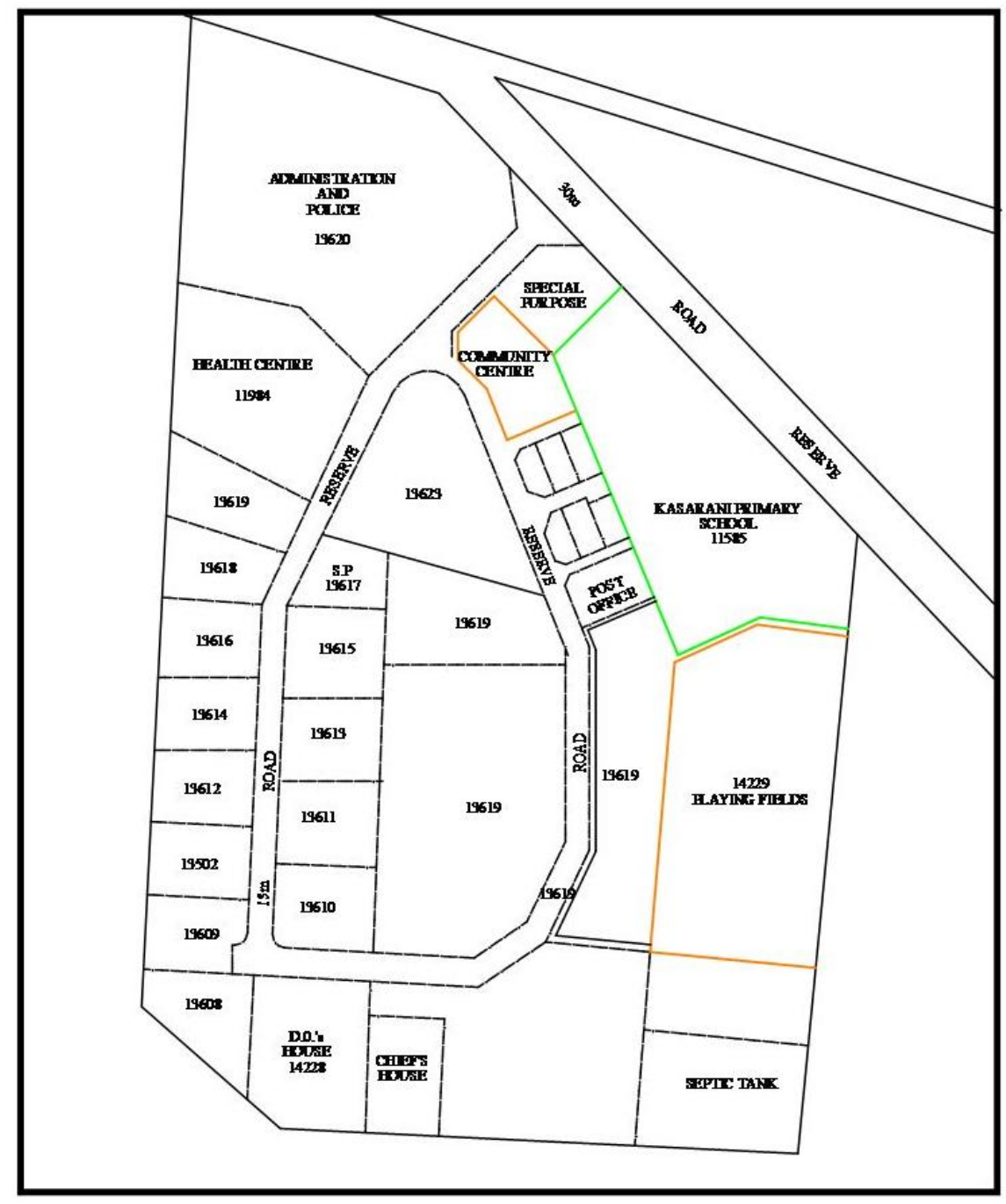

Figure 4: Part Development Plan 1984- Ruaraka Market Centre showing a playing field not located conveniently to the resident users.

Source: Ministry of Lands 2010

\subsubsection{Security and safety}

$95 \%$ of the recreation users considered good security as a very important factor in choice of a particular facility. 65\% preferred the modern security equipment such as Crossed Circuit Television (CCTV) as important device used to respond and enhance security in the recreational facilities. The residents had witnessed incidents of insecurity and hence the quest for improved security. Most of the public facilities in the area though opened for 
use by the residents were unattractive, suffered from the problem of gangs and vandalism than the private facilities. The playing field next to Kasarani Primary School was not well interconnected with pedestrian trails and was overgrown with vegetation. Users of facilities were unable to explore the facilities due to fear of attack. $40 \%$ of the recreation facilities had secluded activities carried out by street boys, gangs, drug dealers and alcoholics. The presence of gang members at the recreation facilities within the neighbourhood was evidenced by displayed symbols on the walls of buildings. Vandalism which was a deliberate destruction of property was reported as a major problem at all recreation facilities. Visitors to recreation facilities also caused damage. They removed signs, rocks and plants; others broke down doors and windows to gain entry to buildings or damaged animal shelters and bird feeding places. It was also reported that damages of property was achieved by defacing it with graffiti which was permanently affixed with acrylic spray paints that were difficult or impossible to remove. This did not ogle well with creating attractive facilities for residents.

\subsubsection{Appropriateness by use for different ages cohorts, gender and disabled persons}

Both public and private recreational facilities in the neighbourhood did not have age specific areas. They were appropriate for use by adults aged between 18-45 years. The shortage of age specific facilities led to children, teenagers, young adults and the aged sharing them. 55\% of respondents stressed for facilities that suited each age cohort in order to cultivate good morals. It was wrong to expose the adults, youth and children in same recreational platforms. In Kasarani location, there were few member only facilities in the neighbourhood. About $15 \%$ of the respondents had registered for use of steam and sauna facilities in a few private hotels in the area. This showed that there were some facilities that did not suit some age cohorts on the basis of African morals and standards. $70 \%$ of the respondents indicated that they were unsatisfied with the way their children spent leisure time. The study revealed that there were no safe playing grounds in the neighbourhood, a scenario that had led to children spending most of their leisure time enjoying home entertainment. They watched and listened to western music transmitted worldwide through the radio, television and internet, which were unsuitable for their physical growth and development. Pie-chart 4 presents the places where children played. $25 \%$ children played at schools and $10 \%$ of respondents said the children have no appropriate to play, $20 \%$ of children playing within the estate were either doing it within their compound or along the estate streets or in house. Those children who could not be contained in the house ended up playing by the roadside or on vacant private plots which they turned to playgrounds. Figure 5 shows children playing alone outside the homestead gate away from the parental surveillance at Clay City Estate. They are playing by the roadside which is a threat to their safety.

Most segments of society continued to experience inequality in recreation. The physically challenged persons, women, the poor and the aged were discriminated on the issue of recreating. They were least facilitated by the family members or by the institutional facilities' management to get access to the recreation facilities.

The shortage of appropriate and safe open spaces for recreation in this area was enamours. The most affected persons were the poor and domestic workers within the estate. On Sundays while the employers were at home with families, the house helps spent their off duty hours in the Roysambu interchange along Thika- Nairobi superhighway (Figure 6). The reason why domestic workers were the majority in this recreational space during the weekends were they could not afford recreational private facilities or commuter cost to the public park such as City Park which was 8km away from Kasarani.

\section{Pie-Chart 4: Places where children play}




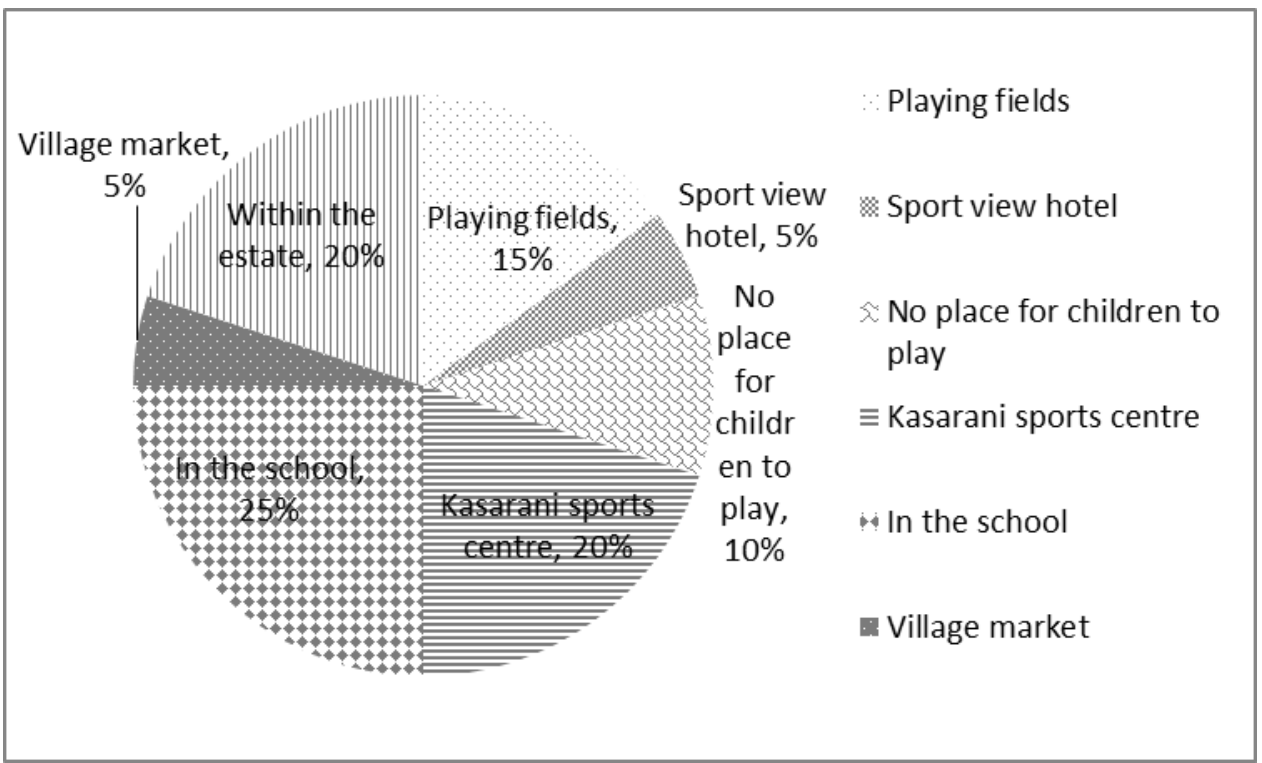

Source: Field survey, 2016

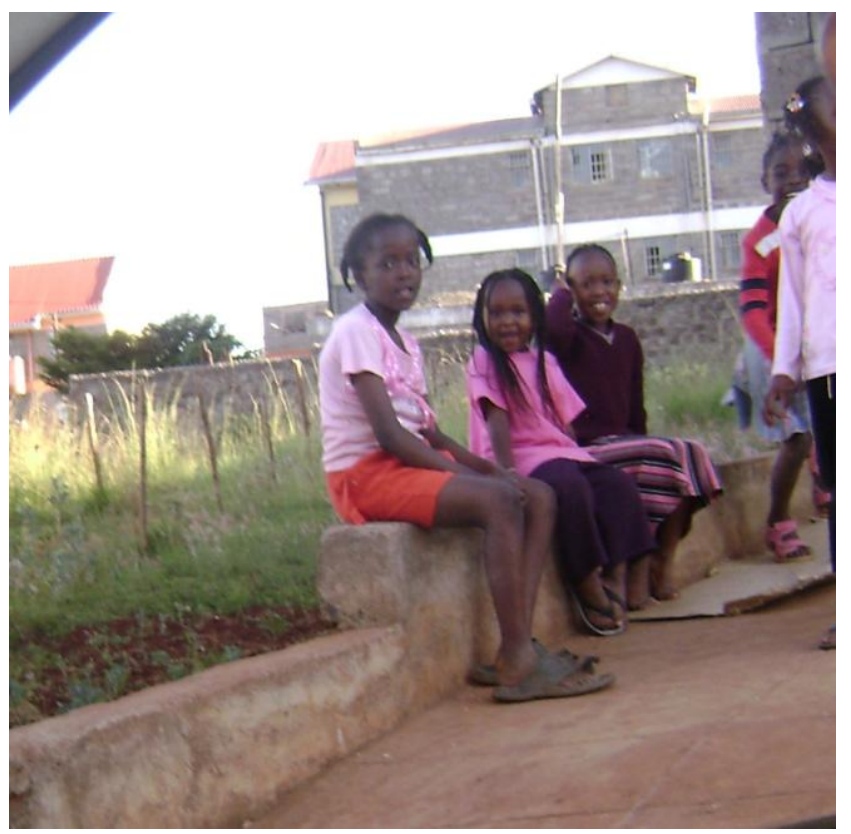

Figure 5: Children seating by the road side in Clay City Estate Source: Field survey, 2016

They used the space as a meeting place and were able to walk return to places they worked before dark. The interchange was about two kilometres from Kasarani shopping centre. The relaxing place at the Roysambu exposed the users to dangers of poor health due to the exhaust fumes they inhale from moving vehicles. The place was common with vehicular accidents, while pedestrians were crossing the multiple lanes at the interchange. 


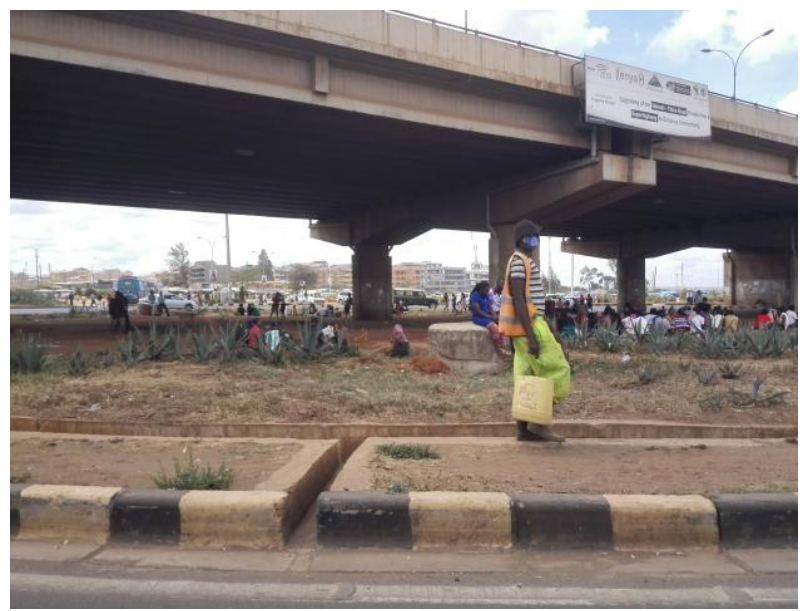

Figure 6: Kasarani residents utilizing the Roysambu interchange as a recreational open space during the weekends

Source: Field survey, 2016

\subsubsection{Leisure time by occupation and gender}

The choice of hours for recreation was upon the employees who were restricted by the agreement with the employer (working time) and students by school hours and family chores. It was established that those with higher education were busier with business or office work load than those who had lower education who were casual workers at their places of work. The irony was that those with money were willing and able to pay to recreate but had less leisure time.Conversely, those with more leisure time and more willing to go to recreate were unable to meet the expense or recreation. Women had a major constraint on recreation time. 55\% of households sample had women who were engaged in bulk of the work inside the home: child care, cooking, cleaning, laundry and shopping with limited or no time for recreation. $65 \%$ of the women respondents said the attitudes and values of the family had placed female gender at a disadvantaged level.

\subsubsection{Variety of services offered}

$70 \%$ of the respondents' preferred one stop facilities with wide range of services that reduce the movement of patrons from one place to another. The facility should satisfy their recreational needs. Users preferred one stop shop facility with a variety of entertainment within the sporting spots i.e. a gymnasium with aerobic facilities, boxing facilities and other fitness equipments, sauna that is working, availability of kids playing facilities, eating places with 'nyama choma' (roast meat) among others. 50\% of the recreational facilities included sporting grounds, swimming pools, boxing, karate floors, pool tables, table tennis, dancing floors, comedy performance platforms and big screens TV/DSTV in pubs.90\% of the respondents considered the ability to host several activities at the same time as a major factor in determining the adequacy of a particular facility. This reduced the level of boredom as every individual could engage in an activity of choice without inconveniencing other family members. For instance, in the Kasarani Aquatic Complex, the parents sat next to the pools looking very bored as the children swam since there was no other recreating activity nearby to engage in.Other important considerations in the usage of facilities cited by users were: availability of trained personnel (80\%), good personalized services (85\%) and advertisement (35\%). Kasarani Aquatic Complex had high preference for people who wanted to learn swimming because they had a variety of swimming pools that could be used by the experienced swimmers and the learners. $95 \%$ of the user respondents considered live performances as important in their choice of recreation facility50\% of the respondents also felt that the provision of recreation facilities was inadequate in such areas as neighbourhood park, golf course, community hall for cultural arts and comedian performances, boat, camel and horse riding. There were no community halls in the neighbourhood. Therefore the community was deprived off the right to gather as neighbours and recreate in form of dancing, watching comedians, participation in music, drama and meetings.

\subsection{Planning Standards}

The Nairobi County Government was one of the institutions mandated by law to ensure proper physical planning and development control is carried out in Nairobi city. But the study found out that the plots earmarked for recreational facilities were converted to residential plots. A case in point was Clay city estate where play fields and social services building were converted to residential plots. These implied that enforcement arm of the local authority is weak and lax. Hence, the intense grabbing of the public land and uncontrolled development were common features in Kasarani neighbourhood.Nairobi City Council (NCC) required 10\% of the land 
surrendered, to develop public amenities before any subdivision plan was approved. The policy was however facing several challenges in recreation provision, particularly where high rise flats were being developed in high density residential zones. Hence, this made a piece of land accommodate more households. In the case of the $10 \%$ land surrendered, the developer sometimes surrenders land poorly located in form of scattered pieces or at the corners of the development scheme leading to their inconvenience, while some were on road frontages where children and residents have hard time to cross busy roads to access them or on water logged sites and former quarry pits where the developers felt were uneconomical to develop.The high density rental developments of tenement were preceded physical planning. For example the housing development in Kasarani was found to be through private developers who buy un-serviced parcels of land from Land Buying Companies who are profit motivated hence allocated every available parcel of land for house development without regard to social amenities like recreation that went with residential zones. Most of the private developers left out a lot of communal social facilities since they were interested in making profits from selling residential and commercial plots, (Rukwaro and Olima (2002). This meant having less recreational facilities. The Planning Standards of recreation facilities was not adhered to during the planning and implementing of the neighbourhood development plan.As a result no surrenders were set aside for community halls, public open spaces and many other social amenities as required by Physical Planning Act, chapter 286 of 1996. This undermined effective provision of recreational facilities required by the highly populated areas.

\subsection{Governance}

Table 3 presents the roles that the major stakeholders carried out and the suggested time frame for implementing certain recreation facilities.

Table 3: The roles of major stakeholders in planning of recreation facilities for Kasarani neighbourhood

\begin{tabular}{|l|l|l|}
\hline Roles & Actors & $\begin{array}{l}\text { Time } \\
\text { Frame in } \\
\text { years }\end{array}$ \\
\hline $\begin{array}{l}\text { Develop nature trails, urban park, creative } \\
\text { play gardens in the area }\end{array}$ & $\begin{array}{l}\text { NCCG, Private sector, } \\
\text { National government, CBOs }\end{array}$ & 10 \\
\hline $\begin{array}{l}\text { Adopt new approaches to planning based } \\
\text { on utilization levels of community } \\
\text { facilities and give first priority to } \\
\text { recreational facilities and }\end{array}$ & $\begin{array}{l}\text { NCCG ational } \\
\text { government }\end{array}$ & 5 \\
\hline $\begin{array}{l}\text { Strengthen the legal and institutional } \\
\text { frameworks and }\end{array}$ & $\begin{array}{l}\text { NCCG and } \\
\text { government }\end{array}$ & 5 \\
\hline $\begin{array}{l}\text { Change policy on public utility land } \\
\text { surrenders }\end{array}$ & $\begin{array}{l}\text { NCCG and } \\
\text { government }\end{array}$ & 5 \\
\hline $\begin{array}{l}\text { Encourage maximum utilization of } \\
\text { recreation facilities }\end{array}$ & $\begin{array}{l}\text { NCCG, Private sector, } \\
\text { National government, CBOs }\end{array}$ & 2 \\
\hline $\begin{array}{l}\text { Formulate community based recreation } \\
\text { policy }\end{array}$ & $\begin{array}{l}\text { NCCG, } \\
\text { government, CBOs }\end{array}$ \\
\hline
\end{tabular}

Source: Field survey, 2016

The governance was seen to multi-agency and participatory by all.

\section{4. CONCLUSION}

The study findings revealed that majority of the residents in Kasarani lacked access to recreational facilities due to affordability where private and some public recreation facilities had started to charge fees to cover their operating costs. The findings also showed that the majority of respondents were economically weak with $50 \%$ of the households spending less than 40 dollars a month while $15 \%$ spent nothing on recreational pursuit. Other factors found to affect planning of recreation facilities were lack of security and safety, congestion, absence of particular facilities; poor site organization inappropriately located within the physical development plans of Kasarani and lack of personalized services. With regard to level of adequacy of the existing facilities, the findings revealed that the facilities especially the public owned and managed were poorly 
maintained, were in short supply and as a result there was congestion in the ones which were available and were in good condition. There was limited variety in delivery of services and majority of public recreational facilities were crowded hence the Nairobi City Council need to consider their carrying capacity. The study revealed that the current physical conditions of the playfields were poor since they were not levelled, were poorly drained and located in poor environments. Recreation facilities being offered at Kasarani had also not catered for vulnerable groups especially the aged and physically challenged persons. Odd activities in recreation facilities were found to be taking root. These activities threaten the life and property of users of the recreation facilities. Finally, there was lack of co-ordination among the major stakeholders in recreation provision in the study area. Along with this, a guiding policy and institutional framework was lacking that would protect recreational land resources from loss to other competing land uses and misuse of the same. The surrender of recreational land by developer was inadequately provided as the development occurred in different estates and plots. In effect the ratio of land use need for developing recreational facilities was not being adhered to by developers as stipulated in the planning standards.

\section{RECOMMENDATIONS}

The recommendation of this study drawn from the findings are;

Accessibility, affordability and proximity: All recreational facilities, whether public or private, need to be equitable to all the users. The principle of equity should be enhanced by making the facilities accessible to the genuine poor persons in the neighbourhood by considering free access to public play fields and parks within the neighbourhood. The recreational facilities also need to be located in suitable areas for all users to access them. However, where it is absolutely necessary minimal user's charges can be imposed for regular maintenance.

Security and safety: Security and safety of the residents should be ensured to encourage participation in recreational activities. The street lighting should be given priority as part of recreation provision initiative and modern equipment such as the Crossed Circuit Television (CCTV) integrated since it augments security in the facilities.Age cohort, gender and diversity of services: Recreational facilities should be adequate for all age cohort and diversity of services. Firstly, diverse recreational activities should be provided for in terms of space, facilities, training and funds. This enables talent building among the residents that can be exploited for the social and economic good of the urban residents. There is need to provide public recreational facilities alongside private ones to regulate the private sector provision of recreation services in the neighbourhood to safe guard against consumer exploitation due to lack of competition. The facilities should be inclusively based on the age cohorts, gender and income levels. This will enable each age cohort to use facilities that are appropriate to them. Hygiene: The recreation facilities should be equipped with adequate, functional and appropriate sanitary fittings such as neat toilets, washrooms/change rooms, drinking water points. The spaces for these sanitation facilities should also be fully furnished with mirrors and lockable doors and waste bins. This would greatly encourage the utilization of these facilities and curb environmental pollution as well as enhancing aesthetic value of the neighbourhood. The sanitation facilities for disabled person should be installed at all different levels of the building.

Funding and training sports personnel: Open fields are highly recommended for the users of the facilities to engage in active leisure activities which are healthy and bring enjoyment and satisfaction to them. The community sports should be recognized and allocated funds in the national budget for economic empowerment of the youth and the mutual benefit since this will serve as a training ground for sportsmen/women. The funds should be available to employ trained physical education personnel as extension officers to train the community on sporting and other physical exercise like swimming. These officers should co-ordinate the community recreation activities and come up with programs to motivate and encourage active participation in active recreation activities by all residents. Inter-neighbourhood competition can be encouraged to promote patriotism and cohesion among community members of diverse regions. Passive leisure activities are also encouraged but they should not consume most of the users' time. The free play areas would serve as a community focal point which would increase their usage and user security.

Planning standards: The Nairobi County Government (NCG) has the legal mandate to provide social services to the residents. The existing planning standards that are based on imported models of ratio of facilities to population should be discarded and a planning model based on utilization levels adopted. The NCG should give recreation facilities first priority in allocation of public amenities spaces. This can be done by treating recreation as a basic human need together with health care and basic education to improve provision of this service. Regular analysis of demand and demographic trends should be carried together with spatial change detection in order to keep pace with the population growth.The Nairobi County Government should ensure proper physical planning and development control is implemented as approved. Consequently, there is need to strengthen the enforcement and compliance office to ensure the latter happens.

Policy and implementation programme: There is need to formulate an urban community based recreation policy and implementation programme that would expand recreational opportunities within urban 
neighbourhoods. It should allow all urban residents to have unlimited right to recreation regardless of their economic status, gender or age. The recreation policy should consider promoting social justice and equity. The policy should be created in such a way that it is focused on maximum utilization of existing recreational facilities, safe guard recreational open spaces from conversion to other urban land uses and set a strategy to reclaim the already grabbed open spaces. The strategy requires political goodwill and community support to achieve its objectives. The policy should also aim at expanding and establishing new recreational investments in the neighbourhood. In order to cultivate public confidence in the technical capability and democratic accountability of the planning system in particular and government in general, there is need to reconcile the expectations of the resident community, local authority and private sector in this urban space.

Governance and integrated planning: There is need to strengthen the legal and institutional framework that guides provision of recreational public open spaces and facilities through practice of good urban governance. There is need for the NCC to encourage co-ordination and cooperation of the interest groups in recreation including resident community, private sector recreation providers, local youth organizations, CBOs, NGOs among others. The institutions in the area and the governing authority should come up with a working partnership to facilitate use of their recreation facilities by the community members. This should be done through a memorandum of understanding between the stakeholders avoid misuse and ensure sufficient maintenance for the good of the client population. A joint approach among the stakeholders is called upon with a view of regional planning. There is need to plan and program recreational facilities together in conjunction with other essential urban social and physical infrastructure like transport, health centres and educational institutions, water and electricity supplies. In planning, recreation should be treated as a public good. The planning policy should guard against conversion of social amenity land to other uses. Planning for the recreation facilities should be based on projection of the future population, which requires visionary planners. Community participation in planning and management of recreational facilities is also encouraged. It creates a feeling of ownership among the residents who will contribute towards long term sustainability of the facilities without misuse or disuse of the same.

\section{REFERENCES}

[1] Dosio, J. (1982). Recreational Planning: A case of Nairobi Municipality. Unpublished Thesis, University of Nairobi.

[2] Goodman, W. \& Freund, E.(1968). Principles and Practice of Urban Planning: International City/County Managers' Association, Washington, DC.

[3] Government of Kenya, (1996). The Physical Planning Act, Chapter 286 of the laws of Kenya, Nairobi: Government Printer.

[4] Government of Kenya (2001). National Development Plan (2002-2008). Effective Management for Sustainable Economic Growth and Poverty Reduction. Nairobi: Government Printers.

[5] Government of Kenya, (2007). Kenya Vision 2030. Nairobi: Government Press.

[6] Government of Kenya (2008). Physical Planning Handbook. Nairobi: Ministry of Lands, Housing and Urban Development.

[7] Government of Botswana (1997). Physical Planning Handbook for Botswana: Gaborone: Ministry of Local Government, Lands and Housing.

[8] Horn, A. (2001). Reflection on the Concept and Conceptualization of the Urban Neighbourhood in Societies in Transition: Case of Pretoria (South Africa).University of Pretoria, South Africa.

[9] Kenya National Bureau of Statistics, (2009). Kenya Census 2009. Nairobi: Government Printers.

[10] Kenya National Bureau of Statistics, (2011). Statistical Abstract 2011. Nairobi: Government Printers.

[11] Kokor, J. (2001). Organizational Considerations for Community Development: Local Governance and Development in Ghana, Spring Centre. University of Dortmund.

[12] Maina, F. (1982). Planning for Recreation and Open Space in Eastlands. Unpublished Thesis University of Nairobi.

[13] Nairobi City Council. (1981). Report on recreation and open space: provision and standards, Nairobi. NCC. Nairobi.

[14] Omondi, P. (1991). Urban Recreation and Tourism Activities with Reference to the City of Nairobi. African Urban Quarterly. 7 (1 \& 2), (1991).

[15] Rukwaro, R., and Olima, W. (2002). Developer Profit Undermines Residents' Satisfaction in Nairobi's Residential Neighbourhood: Implications for Local Government in Kenya. Habitat International. 27(2003), 143-157

[16] Un-Habitat (2002). Role of Cities in Sustainable Development: Health and Living Environments. Elsevier Science Ltd, Nairobi. 